\title{
Did Cinderella Arrive at the Ball? Implications of Contemporary European Education Policies on the Prospects of Early Childhood Education and Care
}

\author{
Jasna Krstovic ${ }^{1}$, Morana Drakulic ${ }^{2}$ \\ ${ }^{1}$ Full Proffesor in tenure, University of Rijeka, Rector's Adviser, Croatia \\ ${ }^{2}$ Postdoctoral researcher, Faculty of Teacher Education in Rijeka, University of Rijeka, Croatia
}

*Corresponding Author: Jasna Krstovic, Full Professor in tenure (retired), Croatia

\begin{abstract}
In times of great challenges and dynamic social changes, Early Childhood Education and Care (ECEC), a profession historically regarded as Cinderella within the system of education, underprivileged and underdeveloped, has in the past few years been slowly but safely climbing the priorities ladder on the national education policies agenda around the world, and has become an essential area of political dialogue and cooperation.

Affirmative messages granting it a key role in laying the foundations for improving the overall quality of life of the future European citizen are welcomed because they have a significant impact on its empowerment and development.

The etiology of these messages is an important pedagogical question. Starting from the firm belief that ECEC plays a significant role in contemporary society, we discuss its place and prospects within the dominant structural-functional discourse, which seriously endangers the very essence of its functioning and existence.

The contemporary ECEC theory, therefore, develops a kind of resistance movements and affirms new paradigms that, in turn, affirm a new view of the child in terms of institutional childhood as its destiny in the 21 st century.
\end{abstract}

Keywords: education policy, prospect, development, new paradigm, ECEC

\section{Context - The Position Of ECEC In Contemporary Documents Of The European EDUCATION POLICY}

In times of great challenges and dynamic social changes, Early Childhood Education and Care (ECEC), a profession historically regarded as Cinderella within the system of education, underprivileged and underdeveloped, has in the past few years been slowly but safely climbing up the priorities ladder on the national education policy agendas around the world, and has become an important area of political dialogue and cooperation (Dalli, Miller, and Urban, 2012, p. 3). We want to believe that this increased interest in ECEC is inspired by the rapid expansion of scientific findings that point to its significant contribution to children's wellbeing as a multidimensional, interactive, dynamic, and contextual process integrating healthy and successful individual functioning and positive social relationships in a quality social environment.

Indeed, we notice an increase in ECEC-related education policies at the European and national level.

At the EU level, there is a respectable number of political and professional bodies which, each from their own scope of work, issue documents with the intention to establish a common understanding of ECEC and to support the Member States in their endeavors to improve the availability and quality of early childhood education and care. They set out the key issues and possible guidelines in accordance with the principle of subsidiarity, i.e., the fact that education is primarily the responsibility of the Member States at the national, regional, and local level. The Union's competences are limited to fostering cooperation as well as supporting and complementing national measures. They are not binding because these are "soft" documents that can inspire the Member States in their strategic thinking about these services (European Commission, 2018a, p. 2). The following paragraphs provide 
Did Cinderella Arrive at the Ball? Implications of Contemporary European Education Policies on the Prospects of Early Childhood Education and Care

an insight into the most relevant documents on the topic.

The document Communication of the European Commission (European Commission, 2017) presents the vision of the European education area based on the New Skills Agenda for Europe and the investments in European youth initiatives (European Commission, 2016). It reinforces and emphasizes the role of ECEC, particularly in setting up solid foundations for lifelong learning and building identity and citizenship. Furthermore, in the Council Recommendation on Promoting Common Values, Inclusive Education, and the European Dimension of Teaching (European Commission, 2018b), the Commission presents a strategy for high-quality, inclusive education geared towards the future, which includes concrete initiatives, and recommends the tools for their realization. In our area, special emphasis is placed on the need to provide quality ECEC and improve the impact that education systems have on equal access to education. In May 2018, the Commission presented an essential document: Proposal for a Council Recommendation on High Quality Early Childhood Education and Care Systems (European Commission, 2018a) aimed at encouraging and supporting the Member States in their endeavor to improve access to their ECEC systems and their quality. The Recommendation recognizes the fact that the first years of life are most favorable for shaping the basic skills and learning capacities and that they can significantly impact later education, employability, as well as other achievements and satisfaction in life. The document recommends explicitly to the Member States to comply with national and European legislation, available resources, and national circumstances and to, in close cooperation with all relevant stakeholders:

- improve access to and the quality of early childhood education and care services

- ensure that early childhood education and care services are accessible, affordable, and inclusive

- support the professionalization of staff depending on existing levels of professional qualification and working conditions

- enhance the development of early years' curricula so that they can meet the wellbeing and educational needs of children

- promote transparent monitoring and evaluation of services at all levels of governance

- Ensure adequate funding and a legal framework for the provision of services, including creating and maintaining tailored national or regional early childhood education and care Quality Frameworks (European Commission, 2018a, p. 9).

In October 2018, the European Commission formed a Working group on Early Childhood Education and Care (ECEC) with the aim of supporting the Commission and the Member States in implementing the actions set out in the Council Conclusions of November 2017 and in the Recommendation proposed in May 2018. In particular, it will allow the Commission to engage with all interested Member States to exchange experiences and good practices, learn from each other and develop targeted policy guidance (European Commission, 2018c, p.1).

Did Cinderella really arrive at the ball? Can we be satisfied with the stated tendencies in the development of interests in ECEC? What is the purpose of raising these questions?

\section{A Problem in Understanding: ECEC in the Jaws of Socio-Structural Conditions AND FACTORS}

In an attempt to provide answers to these questions, we should familiarize ourselves with the etiology of social circumstances within which increased interest in ECEC has emerged. We are dealing here with a predominately affirmed concept of contemporary social rights that seeks to contribute to the achievement of a social Europe for all European citizens. The inter institutional proclamation on the European Pillar of social rights by the Council of the European Commission (Council of the European Union, 2017) established 20 principles and rights, divided into three categories: equal opportunities and access to labor market, dynamic labor markets and fair working conditions, public support/social protection and inclusion. The third category explicitly mentions:

\subsection{Childcare and Support to Children}

- Children have the right to affordable early childhood education and care of good quality.

- Children have the right to protection from poverty. Children from disadvantaged backgrounds have the right to specific measures to enhance equal opportunities (ibid, p. 19). 
Did Cinderella Arrive at the Ball? Implications of Contemporary European Education Policies on the Prospects of Early Childhood Education and Care

Of course, this is by no means disputable; on the contrary, the problem is that the document, despite the aforementioned explicit statement, points to an almost complete abandonment of the effort to promote quality ECEC and thus unreasonably reduces its integrity. The focus is predominately on defining and interpreting the various structural conditions and factors that enable the realization of this right in the dimension of accessibility, i.e., availability, affordability, and inclusion.

Availability is a complex indicator most commonly measured by the number of available places in preschool programs. There is also a broader context, primarily through an emphasis on gender equality and fair access to services, through the guarantee of a place in childcare programs, entry criteria, distance from the place of residence, etc. Affordability or cost accessibility is most often viewed from a parenting perspective - which amount of (family) income goes toward early childhood education and care - with the aim of assessing whether parental participation in program pricing hampers the access of different social groups to the services and whether it makes their labor feasible (Dobrotić, Matković, and Menger, 2018).

The importance of providing access to early childhood education and care and ensuring its affordability and service adaptation to the needs of the family, especially given the needs of disadvantaged children, are highly prioritized in European policy documents. In this respect, we wish to point out the recently adopted Conclusions of the Council of Europe (June 2018), outlined in the Notice as Integrated early childhood development policies as a tool for reducing poverty and promoting social inclusion - Council Conclusions (Council of the European Union, 2018). According to the European benchmark established in the context of the Strategic Framework for European Cooperation in Education and Training (EC, n.d.), at least 95\% of children between the ages of four and the age of compulsory primary education should attend early childhood education and care. Furthermore, the Presidency of the European Council adopted in 2002 the so-called Barcelona objectives (European Commission, 2018d), which has played an essential role in attracting the attention of national policymakers. In these objectives, it is established (in an effort to improve women's participation in the labor market) that $33 \%$ of children under the age of three and $90 \%$ of children between the ages of three and the compulsory school age should have access to ECEC services.

In its 2013 report assessing the current state of affairs, the European Commission (the report focuses solely on the availability of childcare, accessibility, affordability, and quality of available childcare) states that, despite the progress achieved since 2002, available childcare services are still not at the level outlined in the Barcelona objectives, and significant improvements are needed in order to achieve an acceptable level of availability, especially for children under the age of three (European Commission, 2018d).

In 2010, the average inclusion rate for children under the age of three was $29 \%$, with large oscillations in different countries, with eighteen countries being far below the target level. For children above the age of three, the Report states that the center of gravitation remains, for the most part, the national or even regional or local level. All stakeholders, especially national and local authorities and social partners, will need to play an active role in developing the supply of accessible, affordable, and quality services for children (Milotay, 2014, p.3).

In the Report from the Commission to the European Parliament (European Commission, 2018e) on the development of childcare facilities, it is emphasized that in recent years the Member States have made good overall progress in improving the availability of early childhood education and care services. The ET2020 benchmark and the Barcelona objective for children under the age of three have been achieved, unlike those for children between the ages of three and the compulsory school age despite the progress achieved since 2011. However, available institutions of early childhood education and care currently lack additional places, and the demand exceeds the offer in almost every country. Low accessibility, availability, and affordability proved to be some of the main obstacles to using these services. In 2016, 86.3\% of children belonging to the aforementioned age group were enrolled in institutions of early childhood education and care. However, these average values hide significant differences between the Member States, regions, and social groups. Additional efforts are needed to ensure access to high-quality early childhood education and care to their children as soon as their parents request it. Specifically, special measures are needed to enable better access for disadvantaged 
Did Cinderella Arrive at the Ball? Implications of Contemporary European Education Policies on the Prospects of Early Childhood Education and Care

children (European Commission, 2018e).

The problem of availability of ECEC is above all an economic issue. In many European documents, it is pointed out that investing in education is the most profitable type of investment. In economic terms, this is a long-term economic being, and funds spent on early childhood education and care are investments in human capital with significant returns. Already in 2006, in its Communication on Efficiency and Equity in the European Education and Training Systems, the European Commission concluded that the "pre-primary education has the highest returns in terms of achievement and social adaptation of children. Member States should invest more in pre-primary education as an effective means to establish the basis for further learning, preventing school drop-out, increasing equity of outcomes and overall skill levels" (Commission of the European Communities, 2006, p. 5).

\subsection{What about Quality?}

Already this brief overview of the selected documents makes it clear that ECEC has become a part of an integrated package of policy measures aimed at overcoming the most pressing social problems: combating inequality and educational poverty, preventing early school drop-out; it is a tool for improving social cohesion and inclusion, reduction of social exclusion and inequality, achievement of better gender equality with the aim of improving women's participation in the labor market, etc.

However, issues surrounding ECEC quality are almost entirely enveloped in the aforementioned dominant socio-protective, economic, and other aspects. The shifts are slow and barely visible. Why is that so? Milotay (Milotay, 2014) provides a partial answer to this question when she reminds us that, historically, the development of early childhood education and care has been initiated by the need for greater availability of services and institutions so as to (re-)integrate more parents, mainly women, into the labor market; the current rhetoric in the selected documents confirms this. In many policy documents, ECEC is defined as a service subject to market forces.

Furthermore, in most European countries, ECEC is divided into two distinct phases according to age (so-called split system). Consequently, the competencies for managing, regulating, and financing ECEC are shared among different bodies. The Ministry of Health, Social Welfare, and Family Affairs is usually the competent body for younger children, while the Ministry of Education is responsible for providing services to older children. Accordingly, educational guidelines are usually applied only to providing services to older children (European Commission, 2014b).

Also, the European Commission's significant 2014 document contains a particularly important definition of early childhood education and care: Provision for children from birth through to primary education that is subject to a national regulatory framework, i.e., it must comply with a set of rules, minimum standards and/or undergo accreditation procedures. It includes public, private and voluntary sectors; center-based as well as the home-based provision (in the provider's home)(European Commission, 2014a, p.3).

Individual examples of highlighting the problem of a lack of focus on quality ECCE in EU policy documents are sporadic, e.g., early childhood education and care (ECEC) is the starting point and one of the most efficient means for raising proficiency in key competencies, but it faces a double challenge of increasing access and quality. Provision of services for children under three years is particularly problematic. Building on the ECEC quality framework developed by the Member States during the previous work cycle, critical issues for further work include the improvement of access, focusing on the disadvantaged, the professionalization of staff and efficient governance, funding and monitoring systems (European Commission, 2015, p.4).

The abovementioned Eurydice document emphasizes the following: Access and quality are the two main ECEC issues facing policymakers in European countries at present. Ideally, they need to be addressed simultaneously. Providing access for all without ensuring quality might not bring the desired benefits for children. Likewise, ensuring high-quality ECEC without securing enough places might not be an acceptable solution when the broader objective is to provide equitable and efficient education systems (European Commission, 2014a, p. 3). Milotay (2014), therefore, rightly warns that the issue of preschool institutions is an important factor in children's upbringing, care, and education and that their quality has so far not been systematically addressed. The objective now is to emphasize this issue, so that early childhood education and care become seen as inseparable and that the issue of 
Did Cinderella Arrive at the Ball? Implications of Contemporary European Education Policies on the Prospects of Early Childhood Education and Care

availability becomes part of the quality issue.

It was not until 2014 that the ECEC Thematic Working Group developed the first document on quality in early childhood education and care-Proposal for Key Principles of a Quality Framework for Early Childhood Education and Care. This endeavor took place at the European level and in line with the principles of the open method of coordination. Its aim was the creation of a common understanding of the importance of establishing high quality early and preschool education and care throughout Europe and improving the existing practice. The Proposal for Key Principles of a Quality Framework focuses on transversal issues and encompasses ten broad statements of action, each of which calls on the Member States to strengthen the quality of ECEC. The focus is on the revision of key policy moves that would lead to improved quality of early childhood education and care within five key quality dimensions: availability, workforce, curriculum, monitoring and evaluation, and management and financing (European Commission, 2014c).

We could claim that all seems to be in order. However, it is not! Upon more careful inspection, it is still possible to detect that the framers of the ECEC quality policy continue to focus on the social, external aspects of the dimensions mentioned above without significantly addressing the crux of the matter.

At present, in international (and national) debates, social and economic arguments prevail over those that address education, with the tendency to double down in this direction. With such an approach, without affirming a much higher number of qualitative objectives, the EU not only neglects its own responsibility but also exposes children across Europe to unequal conditions. As European citizens, children should be able to count on common rights and privileges that should not be conditioned by their place of birth, social status, ethnicity, etc.

\section{Evaluation of the Position and Prospect of ECEC in Education Policy DOCUMENTS: EDUCATIONAL-CRITICAL DISCOURSE}

We will agree that the affirmative messages that grant ECEC a vital role in establishing a foundation for the improvement of the overall quality of life of the future European citizen are welcomed given that they have a significant impact on its empowerment and development. The selected recent European education policy documents undoubtedly point to the fact that the European Union has afforded ECEC a high place in its political program in the last decade. However, do we need to applaud each message with the same degree of kindness and faith?

By paraphrasing the famous Latin phrase pulchritudo in oculisaspicientisest, we develop a critical discourse based on its reading with the eyes of education experts. In this regard, even a superficial scanning of the selected documents reveals that theetiology behind the messaging is complex, diverse, and multilevel. The language, which places them in the relevant social/educational domain, is a typical education policy expression that is expected, understandable, and acceptable. We are, however, of the opinion that such an expression cannot work if it does not mirror the language of science and profession to which the document refers. A qualitative consensus between politics and science is set as conditio sine qua non! This is the only approach to achieving their optimum functioning as a tool aimed at supporting the Member States in their ambitions to provide high-quality systems of ECEC (European Commission, 2018a).

ECEC is an immanent pedagogical issue. For this reason, contemporary pedagogical science has to provide answers to some of the important questions that arise in the context of the abovementioned events. To back down before them means to renounce their essential duty and task-focused commitment to the appreciation of objective, systematized, and argument-based insights, which it possesses as science in a particular field of research.

It is encouraging to hear the ever-louder voices of education experts, who share a different conception of the contemporary ECEC policy. By accepting the unquestionably important and complex role of ECEC in the current social context, the contemporary ECEC theory and practice conceives new paradigms that address its place, prospects, nature, and the significance of long-term effects within the dominant current utilitarian social paradigm. We could argue that we are developing a kind of "resistance movement" to the growing syndrome of re-conceptualizing the whole social context according to the economic logic and legitimacy, which is mostly based on cost-benefit analyses, 
Did Cinderella Arrive at the Ball? Implications of Contemporary European Education Policies on the Prospects of Early Childhood Education and Care

reducing thereby the overall education to an economic category, (non-)profitable investments, and ultimately to a service that is subject to market forces (Moss, 2017).

It should be noted that the overall quantification of the objectives, statements, and similar formulations related to the position and prospects of ECEC must be accompanied by a clear definition of the values and principles on which services should be based, which have clear implications on the rights of children and their interests, and which make up the European approach to services for preschool children. Moreover, this approach has to overcome mere childcare and be based on an inclusive concept of service that will be multifunctional and open to all children and families. It goes without saying that childcare is indispensable, but this approach must include education, family support, and a democratic practice as well.

A simplified and one-way argumentation of the cost-benefit approach is present in almost all policy documents defining the ECEC development policy. It is stated loudly and continuously that the return on investment in the early stages of education is highest in all levels of education, especially for disadvantaged individuals. The funds spent on early childhood education and care are investments in human capital that bring significant returns. This is, in fact, a reductionist view of the complex social processes that cannot be observed with the dominantly economic logic and legalities. It is not applicable to the education sector in its entirety and especially to ECEC, which necessarily requires a far broader, more open, and multidisciplinary approach. The dominance of this fundamentally reductionist approach, which ignores the bigger picture, is a powerful motive for including science in the work of the framers of education policies (Moss, 2017).

The structurally-functionalist discourse is specifically mirrored in ECEC. It is a kind of conflict of the worlds; a conflict between prose (instrumental rationality and technical practice) and poetry (a way of life that implies emotion, participation, love, joy), which seriously endangers the very essence of its functioning and existence (Vecchi, 2010). We will agree that the education practice of ECEC is hugely complex, multilayered, dynamic, and unpredictable; it is a living organism marked by constant communication and interaction between the adults and children as well as children among each other, whereby the synergy of nurture, care, and education achieves developmental effects. It is an area of emotion, developed ethics of care for the youngest governed by "the laws of poetry," not prose! Vecchi states that human life necessarily consists of both prose and poetry, which are fundamentally deeply intertwined and work in a constant mutual dynamic relationship. Prose is labor, survival, structure-based activity, objectives, and the main space for the utilitarian, technical, and practical. Poetry is a way of life that implies participation, love, desire, and joy. We are therefore rightly warned that, nowadays, the balance between them is severely disrupted (Vecchi, 2010).

Osgood, in her discussion about the new vision of professionalism in ECEC, also vigorously attacks the neo-liberal concept proposed by the education policy, as she establishes the correct way of interpreting or promoting certain discursive truths, in this case, related to the quality of work within the ECEC field. This is a (powerful) discourse of rationality that she wishes to move toward the emotional discourse (Osgood, 2006).

The already mentioned historical "offense" of the preschool care and education profession, seen through the traditional divide between education and care, is still largely functional today. This artificial dilemma arising from a lack of knowledge has its roots in a concept that more appreciates knowledge than skills in which the knowledge about children's learning is perceived as superior to care. This is particularly problematic not because knowledge and education should not be appreciated, but because such an approach devalues the ability to provide care, which is crucial for ECEC (Lally, Torres, \& Phelps, 1993). Therefore, ECEC, characterized by high emotionality and the culture of care and nurturing, has a low "exchange rate" within the dominant utilitarian philosophy. Insisting that ECEC remain at these values necessarily means it cannot satisfy the dominant discourse and is, therefore, further compromised. Therefore, Osgood demands the establishment of an alternative ECEC structure, which as its cornerstone recognizes the unique nature and complexity of preschool work, empowerment of ethics of care, and re-evaluation of the importance of the emotional dimension in working with young children and their families (Osgood, 2015).

We should be greatly concerned by the growing tendency of domination of the clearly measurable outcomes as quality standards in ECEC that are applied in the framework of regulated processes and 
Did Cinderella Arrive at the Ball? Implications of Contemporary European Education Policies on the Prospects of Early Childhood Education and Care

prescribed methods. They are becoming increasingly popular in present-day Europe - from services that are understood as "producers" of narrowly-defined "commodities," such as "childcare" or "careeducational outcomes" that are competing for parent-clients in the open market, to services that are understood as a place of control over children by using technology to achieve predetermined objectives.

The advocacy of the need to develop a different type of narrative is gaining momentum, especially one that would evaluate the complexity and multiplicity, subjectivity and context, coincidence and insecurity instead of the paradigm of modernity, which speaks of quality and return on investment, instrumental rationality and technical practice, of certainty, predictability of objectivity, universality and mastery, of predetermined and measurable outcomes that become the only measure of things in which preschools (and schools) are factories that produce default results and tame, manage, and standardize -places of containment. This paradigm considers that every ECEC phenomenon has multiple meanings, all knowledge has potential, and each experience is subject to interpretation (Moss, 2012).

\section{NeW ECEC PARAdigm as a Foundation for CReating Education Policies}

We are aware that we are faced with an extraordinary and deep social crisis that threatens our collective wellbeing. In these circumstances, creating policies that attempt to overcome it is justified. We agree in this context with the definition of ECEC as a powerful social resource in building a better future. We do not doubt its role in modern society! What we are questioning is the increasingly present agenda in which ECEC, based on the paradigm of modernity, is placed in the position of a magical cure for the overall wellbeing of a sick society, thereby completely neglecting the fact that a technical repair cannot be the solution for structural and systemic problems, inequality, and injustice. Quality ECEC cannot replace a broken society, nor can it be achieved in a society bustling with social inequalities, differences, and divisions. Therefore, investments in ECEC will serve the purpose and yield results only when they are made in democratic, egalitarian, and solidary societies (Moss, 2012).

We should be seriously concerned about the fact that, in the current moment, in ECEC policy documents and international debates, social and economic arguments prevail over care and education with the tendency to double down in this direction. That is what makes all the loud voices that warn of the need to redefine and re-design the preschool field of work, that call for the abandonment of the tendencies that seriously disturb the essence of ECEC primarily in its educational context, which have become rampant and threaten to spread disease to the whole organism, understandable (Urban \&Dalli, 2012). There is a need for greater inclusion of science and scientists into the development of an active dialogue with the creators of education policy. The focus is on revising the key political moves that can lead to qualitative leaps in the further development of early childhood education and care.

We agree with the statement that there has never been a more critical moment than this to "stand above the parapet and shout for what you believe in, as there are still policymakers who do not understand the crucial nature of early years education" (Brock, 2006, p. 6).

Adopting a policy document is impossible if the creators of education policies and scientists do not jointly answer many of the crucial questions. Some of them are axiological - how do we understand education and its purpose, what are the fundamental values in education? What is the ethics of education? What kind of society do we want to build? What do we want for our children here and now and in the future? Some questions are epistemological while others are ontological - Who is a child? What kind of an image of the child and childhood do we aspire to in a rapidly changing society? To ask these questions is to admit that many visions and understandings of the child and childhood are possible, and to provide answers means to make political and ethical choices that are of great importance because this again refers to the value dimension of the problem as its reference point (Moss, 2017).

These are some possible answers:

- Childhood is not just a preparatory phase for a future life, but a life period that has its own values and culture. It is a process of social construction that children and adults jointly build. Childhood is a process that is always contextualized in relation to a particular space, time, and culture, and it varies with respect to a range of conditions and cultures in which it occurs (Slunjski, 2016). 
- The child is a personality from the moment of his birth and should be respected and be taken seriously. He is a social subject that participates, constructs and, to a large extent, determines his own life and development. He is a "rich" child born with great potential that can be expressed in hundreds of ways. He is a child who is actively learning, trying to perceive the meaning of the world from the very beginning, a co-creator of knowledge, identity, culture, and values; a child who is able to live, learn, listen, and communicate, but always in relationships with others. He is a complete child; a child with his own body, mind, feelings, creativity, history, and social identity; an individual whose individuality and independence are interdependent and who needs and wants to be connected with other children and adults. He is a citizen who has his place in society, a subject of rights that society must respect and support (Cagliari et al., 2016).

- Such a child demands and deserves the kind of ECEC based on a holistic and multifunctional approach that presupposes the inseparability of care and education, reason and sentiment, body and mind, which have the potential for countless possibilities: cultural, linguistic, social, aesthetic, ethical, political and economic and which are the meeting place for children and adults in the physical but also in the social, cultural and political sense of the word.

- The contemporary ECEC affirms the ethics of care that is present in all activities and relationships. Nurturing should be placed in a broader context as an integral and intrinsic part of the child's care and education, a great objective that recognizes the importance of space and play in the child's life and which includes learning, social relationships, ethics, aesthetics, and the total benefit in the broadest sense of the word.

- Such ECEC institutions should not only be open to new objectives and roles but to results that are not pre-determined. They are envisioned as public institutions, as a place for discussion and space for children, i.e., for meetings and gatherings where children and adults come together and dedicate themselves to something, where they can talk, listen, and discuss with the aim of exchanging opinions. It is a place of ethical and political practice, a place for research and creativity, coexistence and joy, critical thinking and emancipation. It is a place of building individuality and independence, but also a place of empowerment of interdependence and solidarity without which there is no individuality and independence. Such institutions are not a substitute for the family; they rather complement and provide support, and offer additional opportunities for children and parents.

- "The future-building school acts as a powerful platform within the community for creating a conversation about the future." It is a place of dialogue and discussions about the future as it brings together children, parents, grandparents, community organizations, and staff to ask questions about the future within the community and to explore what alternatives to the future they could create for their children. Such institutions are a powerful democratic resource and public space that allows young people and communities to imagine the visions of the future that are presented to them and to work together through traditional and new democratic practices in order to compete for a lasting future for all (Facer, 2011).

\section{REFERENCES}

[1] Dalli, C., Miller, L. \& Urban, M. (2012). Early Childhood Grows Up: Towards a Critical Ecology of the Profession. In Miller, L., Dalli, C., \& Urban, M. (Eds.). Early childhood grows up: Towards a critical ecology of the profession (pp.21-35). Springer Dordrecht Heidelberg London New York.

[2] European Commission (2018a). Proposal for a Council Recommendation on High Quality Early Childhood Education and Care Systems. Retrieved from https://eurlex.europa.eu/resource.html?uri=cellar:05aa1e 50-5dc7-11e8-ab9c01aa75ed71a1.0003.02/DOC_1\&format=PDF

[3] European Commission (2017). Communication from the Commission to the European Parliament, the Council, the European Economic and Social Committee and the Committee of the Regions. Strengthening European Identity through Education and Culture. The European Commission's contribution to the Leaders' Meeting in Gothenburg. Retrieved from https://eur-lex.europa.eu/legalcontent/EN/TXT/PDF/?uri= CELEX:52017DC0673\&from=HR

[4] European Commission (2016). Communication from the Commission to the European Parliament, the Council, the European Economic and Social Committee and the Committee of the Regions. A New Skills 
Did Cinderella Arrive at the Ball? Implications of Contemporary European Education Policies on the Prospects of Early Childhood Education and Care

Agenda for Europe. Working Together to Strengthen Human Capital, Employability and Competitiveness. Retrieved from https://eur-lex.europa.eu/legal-content/EN/TXT/PDF/?uri=CELEX:52016DC0381\&from= HR

[5] European Commission (2018b). Proposal for a Council Recommendation on Promoting Common Values, Inclusive Education, and the European Dimension of Teaching. Retrieved fromhttp://www.ipex.eu/IPEXL-WEB/dossier/document/COM20180023.do?appLng=EN

[6] European Commission (2018c). Register of Commission Expert Groups and Other Similar Entities. Retrieved from http://ec.europa.eu/transparency/regexpert/index.cfm?do=groupDetail.groupDetailPDF\& groupID=3623

[7] Council of the European Union (2017). European Pillar of Social Rights. Retrieved from https://ec. europa.eu/commission/sites/beta-political/files/social-summit-european-pillar-social-rights-book let_en.pdf

[8] Dobrotić, I., Matković, T., \& Menger, V. (2018). Analizapristupačnosti, kvalitete, kappa citetaifinanciranjasustavaranogaipredškolskogodgojaiobrazovanjauRepubliciHrvatskoj.Zagreb. Ministarstvozademografiju, obitelj, mladeisocijalnupolitiku.

[9] Council of the European Union (2018). Integrated Early Childhood Development Policies as a Tool for Reducing Poverty and Promoting Social Inclusion Council Conclusions. Retrieved from http://data.consilium.europa.eu/doc/document/ST-10306-2018-INIT/en/pdf

[10] European Commission (n.d.). European Policy Cooperation (ET2020 framework). Retrieved from https://ec.europa.eu/education/policies/european-policy-cooperation/et2020-framework_en

[11] European Commission (2018d). Report from the Commission to the European Parliament, the Council, the European Economic and Social Committee and the Committee of the Regions. Barcelona objectives Report from the Commission to the European Parliament, the Council, the European Economic and Social Committee and the Committee of the Regions. Retrieved from https://ec.europa.eu/info/sites/info/files/ bcn_objectives-report2018_web_en.pdf

[12] Milotay, N. (2014). Razvojpolitikaranogipredškolskogodgojaiobrazovanjaod '90-tih u EU. Djeca u Europi, 6(11), 4-7. Retrieved from https://hrcak.srce.hr/145162

[13] European Commission (2018e). Report from the Commission to the European Parliament, the Council, the European Economic and Social Committee and the Committee of the Regions on the Development of Childcare Facilities for Young Children With a View to Increase Female Labour Participation. Strike A Work-Life Balance for Working Parents and Bring about Sustainable Aad Inclusive Growth in Europe (the "Barcelona objectives"). Retrieved from https://eur-lex.europa.eu/legal-content/EN/TXT/PDF/?uri= CELEX:52018DC0273\&from=HR

[14] Commission of the European Communities (2006). Communication from the Commission to the Council and to the European Parliament. Efficiency and Equity in European Education and Training Systems. Retrieved from https:/eur-lex.europa.eu/legal-content/EN/TXT/PDF/?uri=CELEX:52006DC0481\&from= EN

[15] European Commission (2014b). Key Data on Early Childhood Education and Care in Europe. Eurydice and Eurostat Report. 2014 Edition. Retrieved from https://ec.europa.eu/eurostat/documents/3217494/ 5785249/EC-01-14-484-EN.PDF/cbdf1804-a139-43a9-b8f1-ca5223eea2a1

[16] European Commission (2014a). Eurydice Policy brief. Early Childhood Education and Care 2014. Retrieved from https://publications.europa.eu/hr/publication-detail/-/publication/25c63f11-c2cb-4c4ca3cb-85d9b1eab93b/language-en

[17] European Commission (2015). Communication from the Commission to the European Parliament, The Council, The European Economic And Social Committee and the Committee of the Regions. Draft 2015. Joint Report of the Council and the Commission on the Implementation of the Strategic Framework for European Cooperation in Education and Training (ET2020). New Priorities for European Cooperation in Education and Training. Retrieved from https://eur-lex.europa.eu/legal-content/EN/TXT/PDF/?uri= CELEX:52015DC0408\&from=EN

[18] European Commission (2014c). Proposal for Key Principles of a Quality Framework for Early Childhood Education and Care. Report of the Working Group on Early Childhood Education and Care under the Auspices of the European Commission. Retrieved from http://ec.europa.eu/assets/eac/education/policy/ strategic-framework/archive/documents/ecec-quality-framework_en.pdf

[19] Moss,P. (2017). Power and Resistance in Early Childhood Education: From Dominant Discourse to Democratic Experimentalism. Journal of Pedagogy, 8(1), 11-32. Retrieved from https://eric.ed.gov/ ?id=EJ1153267

[20] Vecchi, V. (2010).Art and Creativity in Reggio Emilia. London and New York: Routledge. 
Did Cinderella Arrive at the Ball? Implications of Contemporary European Education Policies on the Prospects of Early Childhood Education and Care

[21] Osgood, J (2006). Deconstructing Professionalism in Early Childhood Education: Resisting the Regulatory Gaze. Contemporary Issues in Early Childhood, 7(1), 5-14. Retrieved from https://eric.ed.gov/?id= EJ904954

[22] Lally, R. L., Torres, L. Y., \& Phelps, P. C. (1993). Caring for Infants and Toddlers in Groups: Necessary Considerations for Emotional, Social, and Cognitive Development. Based on Plenary Presentation at ZEROTO THREE's Eighth Biennial National Training Institute. Washington, DC.

[23] Osgood (2015). Postmodernist Theorising in ECEC: Making the Familiar Strange in Pursuit of Social Justice. In T. David, S. Powell., K. Sylva. (Eds) Routledge Handbook of Philosophies and Theories of Early Childhood Education and Care, London: Taylor \& Francis.(pp. 157-164).

[24] Moss, P. (2012) Experimenters, Critical Thinkers and Democrats: The Role of Educators in a World of Conflicting Alternatives. Plenary speech at ISSA DECET Conference 'Sukonstrukcija professional nograzvoja: Put premakvaliteti, pravednostiiuvažavanjurazličitosti u odgojuiobrazovanju'. Opatija.

[25] Urban, M. \&Dalli, C. (2012). A Profession Speaking and Thinking for Itself. In Miller, L., Dalli, C., \& Urban, M. (Eds.). Early childhood grows up: Towards a critical ecology of the profession. Springer Dordrecht Heidelberg London New York. (pp.157-175)

[26] Brock, A. (2006).Dimensions of Early Years Professionalism: Attitudes versus Competence. Reflection paper on Training Advancement and Co-operation in the

[27] Teaching of Young Children (TACTYC). Retrieved October 21, 2006, from http://www.tactyc.org.uk

[28] Slunjski,E. (2016). Izvanokvira 2. Promjena, odkompetentnogpojedincaiustanove do kompetentnezajed niceučenja. Zagreb: Element.

[29] Cagliari, P., Castagnetti, M., Giudici, C., Rinaldi, C., Vecchi, V., \& Moss, P. (Eds.). (2016). Loris Malaguzzi and the Schools of Reggio Emilia: A Selection of Writings and Speeches, 1945-1993. London: Routledge.

[30] Facer, K. (2011). Learning Futures: Education, Technology and Social Change. Routledge. Retrieved fromhttp://www.bpums.ac.ir/UploadedFiles/CourseFiles/[Keri_Facer]_Learning_Futures_Education,_Tec hnolo_f9e20225.pdf

Citation: Jasna Krstovi, Morana Drakulic. "Did Cinderella Arrive at the Ball? Implications of Contemporary European Education Policies on the Prospects of Early Childhood Education and Care." International Journal of Humanities Social Sciences and Education (IJHSSE), vol 6, no. 3, 2019, pp. 40-49 doi: http://dx.doi.org/10.20431/2349-0381.0603006.

Copyright: (C) 2019 Authors. This is an open-access article distributed under the terms of the Creative Commons Attribution License, which permits unrestricted use, distribution, and reproduction in any medium, provided the original author and source are credited. 